\title{
ANÁLISE DA MORFOMETRIA DO RELEVO DA BACIA DO RIO CABEÇA (SP)
}

\author{
Patricia Borges Silveira $^{(a)}$, Cenira Maria Lupinacci ${ }^{(b)}$ \\ (a) Departamento de Planejamento Territorial e Geoprocessamento /Universidade Estadual Paulista "Júlio de Mesquita \\ Fiho", patygeo@gmail.com \\ (b) Departamento de Planejamento Territorial e Geoprocessamento/Universidade Estadual Paulista "Júlio de Mesquita \\ Filho", cenira@rc.unesp.br
}

\section{EIXO: SISTEMAS GEOMORFOLÓGICOS: ESTRUTURA, DINÂMICAS E PROCESSOS}

\section{Resumo}

O presente artigo tem por objetivo analisar os elementos morfométricos da Bacia do Rio Cabeça (SP), a fim de avaliar as áreas potencialmente mais suscetível aos processos geomorfolóficos. Para isso foram elaborados mapeamentos de declividade e profundidade de drenagem. Dessa maneira, através da análise desses mapeamentos, foi possível identicar as zonas com maiores e menores índices morfométricos e consequentemente aquelas que necessitam de maior preservação.

Palavras chave: Bacia hidrográfica, declividade, profundidade de rios, Depressão Periférica Paulista e Cuesta.

\section{Introdução}

A presente pesquisa visa estudar o relevo da bacia rio Cabeça, um dos principais afluentes da bacia do rio Corumbataí, localizada no setor centro-leste do estado de São Paulo, situado entre as coordenadas $22^{\circ} 19^{\prime}$ e $22^{\circ} 14 \mathrm{~S}$ e $47^{\circ} 46^{\prime}$ e $47^{\circ} 42^{\prime}$ ' W. A área de estudo posiciona-se em parte no município de Rio Claro, de Ipeúna ao sudeste, e de Itirapina, ao norte da bacia. Os terrenos da área distribuem-se entre as províncias da Depressão Periférica Paulista e Cuestas Basálticas.

A Depressão Periférica Paulista é uma das mais características unidades geomorfológicas e geográficas do estado. Segundo Almeida (1974), a denominação dada a esta por L.F. de Moraes Rego é perfeitamente compreensível, pois se trata de uma área rebaixada pela erosão, localizada entre o Planalto Atlântico e as cristas da também elevada Cuestas Basálticas.

De acordo com Almeida (1974), a subsidência da Bacia do Paraná, no Cretáceo Superior, contribuiu para que ocorresse o recobrimento do basalto por sedimentos detríticos pertencentes ao Grupo Bauru. Ab' Saber (1969) afirma que essa subsidência foi o último "re-embaciamento" da Bacia Sedimentar do Paraná. Após este movimento, houve um soerguimento que proporcionou a superimposição da drenagem, a qual, 


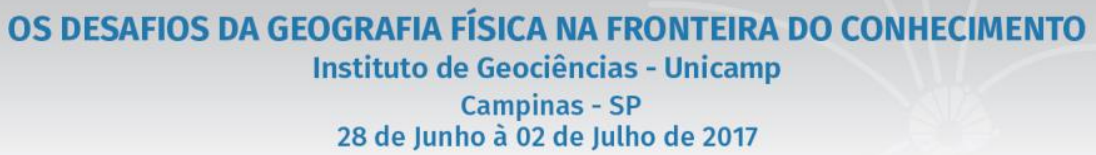

ao erodir a cobertura cretácea, fez com que os derrames fossem expostos, dando origem aos fronts cuestiformes.

Diante dos fatos apresentados, o objetivo desse artigo é analisar os elementos morfométricos do relevo da bacia do rio Cabeça, obtendo dados detalhados sobre a dissecação e declividade da mesma. Através do estudo sobre a morfometria, áreas potencialmente mais suscetíveis aos processos geomorfológicos foram identificadas, analisadas e discutidas nesse presente artigo.

\section{Técnicas}

Inicialmente, foi elaborada a base cartográfica da Bacia do Rio Cabeça, a qual foi criada através das cartas topográficas do IBGE, na escala 1:50.000, de 1971. Para tal realização necessitou-se de quatro cartas para que o limite da área de estudo fosse estabelecido: Rio Claro (SF-23-M-I-4), Corumbataí (SF-23-Y-A-I-2), Itirapina (SF-23-M-I-3) e São Carlos (SF-23-Y-A-I-1). Em seguida, a carta clinográfica e de profundidade foram construídas.

A carta de profundidade de drenagem foi elaborada segundo os pressupostos de Hubp (1988), com base em uma metodologia adaptada para o meio automático, utilizando o programa Arc Gis 9.2. Segundo Hupb (1988), a carta de profundidade de drenagem é construída a partir da mensuração do entalhamento da drenagem, isto é, no desnível altimétrico entre os terrenos da bacia.

Primeiramente, ao elaborar essa carta foram identificados os cursos fluviais e seus divisores de água. $\mathrm{O}$ mapa foi divido em figuras geométricas quadriláteras, sendo o tamanho dessas definidas de acordo com as condições geomorfológicas; para essa pesquisa o tamanho estabelecido, a partir de testes, foi de $300 \mathrm{~m}$ de lado. Posteriormente, o desnível altimétrico foi encontrado em cada forma geométrica, de modo a conter seu máximo e mínimo valor. Na próxima etapa é realizado o cálculo, o qual é anotado no ponto central da figura. Com o resultado obtido, é feita a interpolação desses valores com os vizinhos, por método linear, a fim de delimitar as isolinhas. Após, o produto foi transformado em Raster, a fim de melhorar sua qualidade.

A carta clinográfica permite avaliar os setores que potencialmente são mais suscetíveis a erosão em função de apresentarem maiores declives. Para construir tal carta, torna-se necessário formular o MNT (Modelo Numérico do Terreno), construindo uma malha triangular ou TIN (Triangular Irregular Networks), a qual se refere a uma estrutura vetorial que forma uma topologia do tipo arco nó e representa a superfície por meio de faces triangulares interligadas. Depois desse procedimento, o produto gerado é transformado em Raster para que as falhas sejam minimizadas. Assim, foi possível estabelecer as classes, 


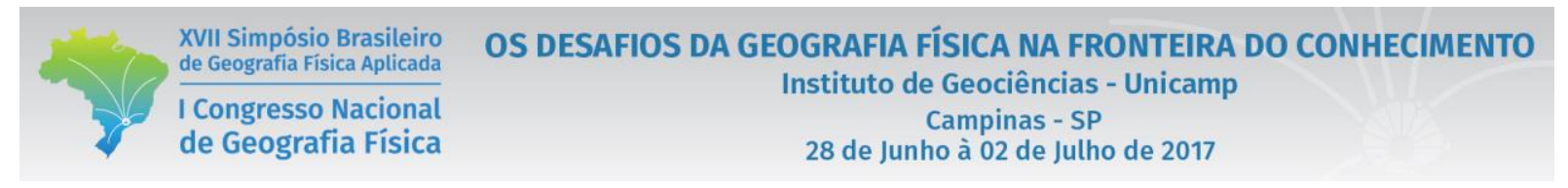

as quais foram retratadas por cores, sendo os tons mais intensos utilizados para os maiores declives. As cores foram determinadas de acordo com a rosa cromática.

\section{Análise dos Resultados}

Analisando a carta de profundidade de drenagem (figura 1), constatou-se que na porção norte da bacia, onde se localiza o front da cuesta, a dissecação do relevo se apresenta bem acentuada, devido aos processos de derramamento de basalto que atuaram na região, dando origem ao referido degrau topográfico. De acordo com Almeida (1974), a extremidade dos derrames basálticos em São Paulo se caracteriza pelas elevadas altitudes e as Cuestas festonadas, que foram formadas pelo pequeno mergulho regional das camadas a noroeste.

Carta de Profundidade de Drenagem da Bacia do Rio Cabeça (SP)

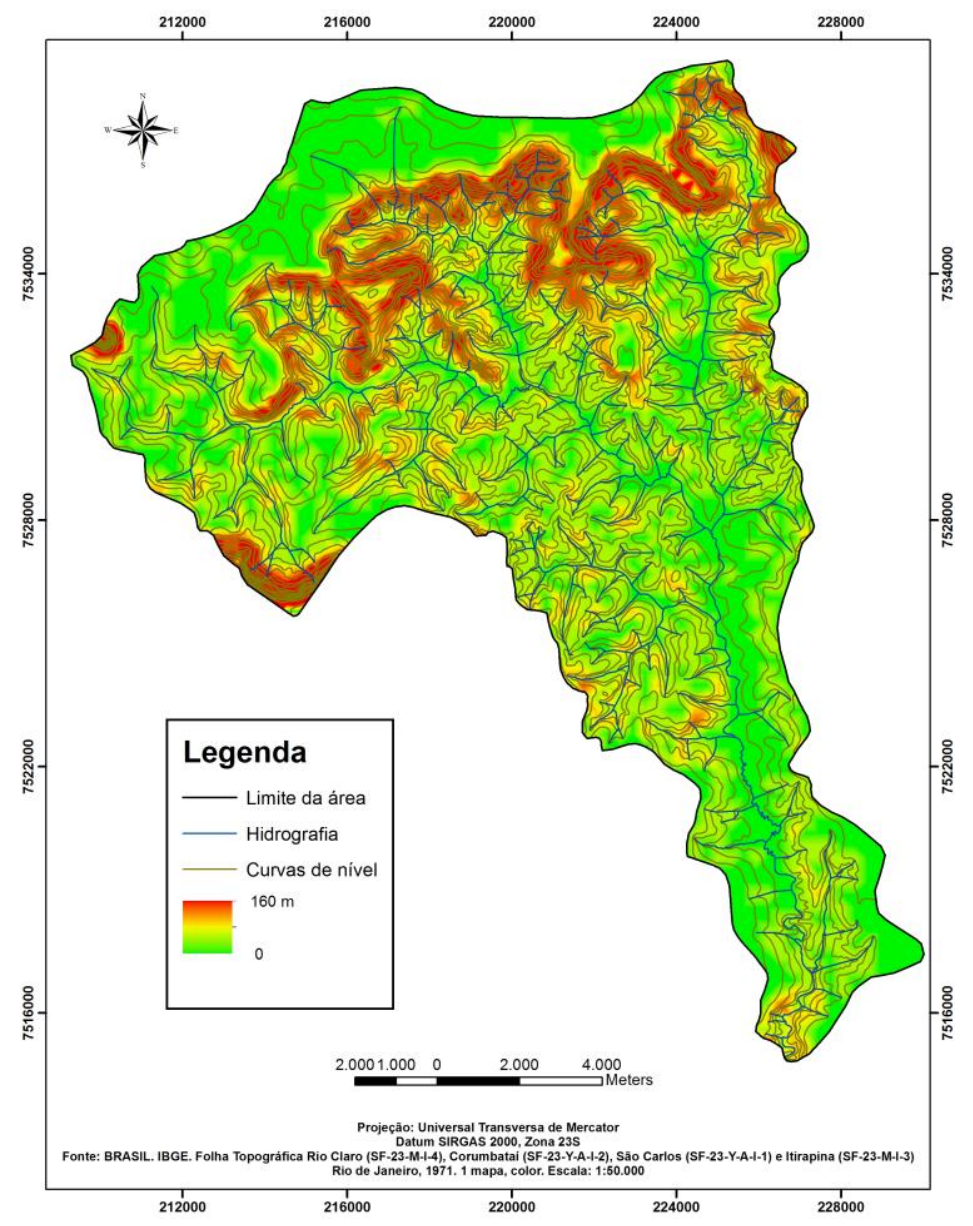

Figura 1: Carta de Profundidade de Drenagem da Bacia do Rio Cabeça (SP) 


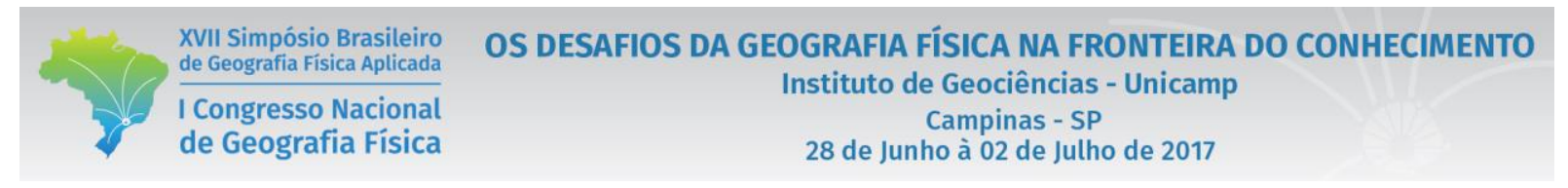

A carta clinográfica (figura 2) releva novamente que maiores índices de declividade estão no setor norte, devido as características litológicas e aos movimentos que a região de estudo foi submetida. Os processos geomorfológicos podem ser intensificados nessa porção; como Fúlfaro (1989) explica que são muito comuns os deslizamentos de blocos de arenito e basalto, sendo o solo pouco espesso e predominantemente litólico. Na porção sul, baixos índices de declividade foram encontrados, caracterizando a Depressão Periférica Paulista.

\section{Carta Clinográfica da Bacia do Rio Cabeça (SP)}

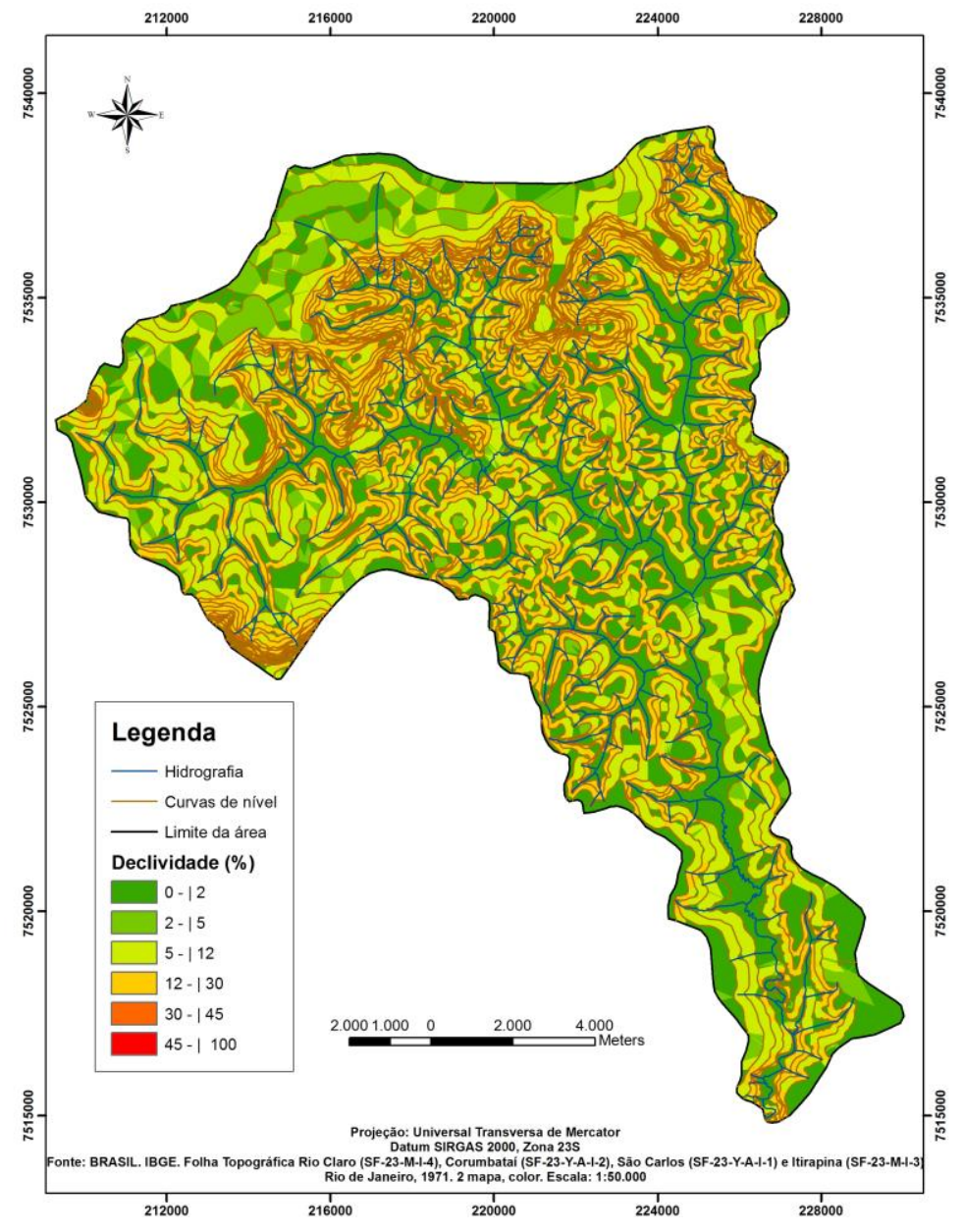

Figura 2: Carta clinográfica da Bacia do Rio Cabeça (SP)

De acordo com os mapas analisados anteriormente (figuras 1 e 2), fica claro a ação da drenagem no configuração do relevo da bacia estudada, indicando as áreas que potencialmente podem estar mais sujeitas aos processos geomorfológicos, devido ao grau de declive acentuado ou ainda pelo grande desnível altimétrico entre os terrenos. Facincani (2000) em sua pesquisa identificou zonas de dissecações 
diferenciadas, como os vales, os quais possuem vertentes retilíneas a convexas, cujo padrão das bacias é predominantemente dendrítico-retangular. A autora destaca também as áreas que apresentam essas características, como os vales dos afluentes do rio Corumbataí, setor que engloba o rio Cabeça.

\section{Considerações Finais}

Para a análise em questão a metodologia se mostrou adequada, pois os objetivos foram atingidos. Como observado, tanto na carta clinográfica quanto na de profundidade de drenagem, o setor norte se destacou por possuir índices morfométricos altos. Enquanto que, no setor sul, os índices foram baixos, principalmente no canal principal do Rio Cabeça, região que pertencente a vasta Depressão Periférica Paulista. Assim, cabe destacar que a porção com maiores índices, devem ser áreas mais protegidas, a fim de evitar que processos erosivos e movimentos de massa se instalem, provocando desastres naturais.

\section{Agradecimentos}

À Fundação de Amparo à Pesquisa do Estado de São Paulo (FAPESP), no 2016/19564-0, pela contribuição com o estudo.

\section{Referências Bibliograficas}

AB'SABER, A. N. Um conceito de Geomorfologia a serviço das pesquisas sobre o Quaternário. Geomorfologia, São Paulo, v.18, p.01-23, 1969.

ALMEIDA, F. F. M. Fundamentos geológicos do relevo paulista. São Paulo: Universidade de São Paulo, 1974. (Série Teses e Monografias n.14).

FACINCANI, E. M. Morfotectônica da Depressão Periférica Paulista e Cuesta Basáltica: regiões de São Carlos, Rio Claro e Piracicaba - SP. 2000. 222 f. Tese (Doutorado em Geologia Regional) - Instituto de Geociências e Ciências Exatas, Universidade Estadual Paulista, Rio Claro, 2000.

FÚlFARO, V. J; BARCELOS, J.H. Movimentação verticais e a evolução da Depressão Periférica e a escarpa da Serra Geral em São Paulo: In: SIMPÓSIO DE GEOLOGIA DO SUDESTE DO SUDESTE,1, Rio de Janeiro, Boletim de Resumos ...Rio de Janeiro, SGB, 1989, p. 109-110.

HUBP, J. I. L. Elementos de Geomorfologia Aplicada (Metodos Cartograficos). Mexico, D. F.: Instituto de Geografia, Universidad Nacional Autonoma de Mexico, 1988. 128 p. 